\title{
Causes and Outcomes of Dental Malpractice Litigation in the Riyadh Region of the Kingdom of Saudi Arabia
}

\author{
Amjad Sulaiman Aldahmashi ${ }^{\mathrm{a}}$ b Mohamed Abdulmohsen Alqurashi ${ }^{\mathrm{b}}$ \\ Mohammed Khaled Al-Hanawi ${ }^{\mathrm{b}, \mathrm{c}}$ \\ ${ }^{a}$ Assistant Agency of Primary Healthcare Centers, Ministry of Health, Riyadh, Saudi Arabia; bepartment of Health \\ Services and Hospital Administration, Faculty of Economics and Administration, King Abdulaziz University, Jeddah, \\ Saudi Arabia; 'Health Economics Research Group, King Abdulaziz University, Jeddah, Saudi Arabia
}

\section{Keywords}

Dental malpractice · Dental negligence · Dentist · Litigation · Saudi Arabia

\begin{abstract}
Introduction: Every health organization aims to provide high-quality service and promote patient safety. However, achieving these goals can be challenging in many healthcare systems around the world. In dentistry, dentists can face medicolegal issues, which can be overcome by exploring the reasons for dental malpractice litigation. In this study, we aim to identify the most common causes and outcomes of dental malpractice litigation in the Kingdom of Saudi Arabia. Methods: This is a retrospective study. We reviewed all closed cases in dentistry as decided by the Medico-Legal Committee of Saudi Arabia in the Riyadh region over a period of 5 years and 3 months, from January 1, 2014, to March 31,2019 . Descriptive analysis was used to examine the phenomenon of dental malpractice claims. Results: In total, 151 claims were analyzed. As per our findings, it was determined that the number of closed claims had increased, with the highest number of claims (35\%) related to the prosthodon-
\end{abstract}

karger@karger.com www.karger.com/sjh

Karger $\stackrel{\text { ' }}{5}$

GOPEN ACCESS
(C) 2021 The Author(s)

Published by S. Karger AG, Basel

This is an Open Access article licensed under the Creative Commons Attribution-NonCommercial-4.0 International License (CC BY-NC) (http://www.karger.com/Services/OpenAccessLicense), applicable to the online version of the article only. Usage and distribution for commercial purposes requires written permission. tics specialty, followed by endodontics specialty (31\%). The most common causes of litigation were failure to conduct the procedure properly (31.5\%) and poor documentation (19.7\%). With respect to litigation outcomes, 54\% ended up with verdict in favor of the plaintiff. Conclusions: It was determined that there is a rising trend of malpractice litigation in the dentistry field; thus, measures should be taken to address these concerns.

(C) 2021 The Author(s).

Published by S. Karger AG, Basel

\section{Introduction}

Patient safety has emerged as a significant and growing public health challenge worldwide. In addition, adverse events that occur on patients are undoubtedly one of the top 10 leading factors in disability or death worldwide [1]. Therefore, studies examining patient safety have increased drastically, with emphasis on preventing the occurrence of medical malpractice and reducing the cost of adverse events [2].

Under litigation systems, there is a legal liability for making medical errors; this is to compensate patients 
who have been harmed or injured due to negligence [3]. If a patient decides to sue a dental professional, in this case, the patient becomes the plaintiff and the dental professional the defendant [4].

The Oxford English Dictionary defines malpractice as inappropriate, illegal, or negligent practitioner behavior [5]. Negligence generally requires specific elements such as duty of care, breach of duty, and, lastly, harm and causation, which means the injury or harm that affects the patient is due to a defect in the duty of care [6]. There are 2 standards of care aspects: the first is the specific actions or decisions that are related to professional duty, while the second is the policies and procedures that are followed in order to decide on a certain action [7]. Medical practice standards are used either to add credence to expert witnesses, to impeach an expert witness, or to protect a dentist who has followed the guidelines as a standard of care [8].

A breach of duty occurs when a healthcare professional fails to meet medical practice standards. However, when a potential violation of accepted professional practices occurs, it has to be determined according to the professional's standard of comparable duty to determine if there is a breach of duty in the healthcare practice [9]. In 2011, a study conducted by Todd [10] showed that many of the claims reported to court were not given final legal decisions due to the absence of a breach of duty, which means that this breach is an essential matter in all cases.

According to the Article 27 of the Law of Practicing Healthcare Professions of the Kingdom of Saudi Arabia (KSA), there is a list of practices that are considered as malpractice; these include making errors during treatment, failure to provide appropriate follow-up or supervision, having insufficient knowledge and skills about the medical field of specialization, or failure to seek consultation whenever needed [11]. Any action decreasing the liability or holding a healthcare professional accountable shall be considered invalid. The KSA has exerted significant efforts in developing its medical facilities [12], using up-to-date techniques and advanced methodologies and improving its human resources to provide high-quality healthcare [13].

Patients, or any of their relatives (in the event of the death of the patient), have the right to ask for compensation for harm or injury due to medical errors through litigation [14]. The medical litigation process begins with the plaintiff filing a complaint document demonstrating the bad outcome he/she has received [15]. According to Article 40 of the Law of Practicing Healthcare Professions of Saudi Arabia, the complaint is reviewed by a competent committee at the directorate of health affairs/medical city or specialist hospitals, depending on where the complaint has been presented [11]. The committee's main responsibilities are to meet both the plaintiff and the defendant and review the medical records to determine if any error has occurred. If an error has been found, the committee sends a recommendation to the authorized person who will then complete the investigation. However, if the committee finds the dental practitioner is not at fault, the members will discuss their findings with the complainant. If the complainant is not satisfied, the case will be referred to a higher committee [14].

The Medico-Legal Committee (MLC) in the KSA is a higher committee that completes the investigation and process to reach a final decision regarding a medical malpractice claim. This committee's chairperson is a judge appointed by the Minister of Justice, while the rest of its members are from the Ministry of Health $(\mathrm{MOH})$ and the Ministry of Education [11]. Once the claim is referred to the MLC, the investigation process continues, wherein all the records of the interviews conducted with people on both sides, of the claimant and the plaintiff, are reviewed to make a final decision on the complaint as per the Medical Practice Regulations, which is carried out in accordance with the professional principles and as regulated by the Islamic Sharia. After a decision is made on the complaint or an agreement is concluded between the plaintiff and the defendant on a certain settlement, the claim is then closed. Both the plaintiff and the defendant have the right to appeal against the committee's decision [15]. In regard to the dentistry field, few programs have been implemented to promote patient safety, and, at the same time, there are little well-studied data on adverse events [16].

Thus, in this study, we aimed to review the claims of the cases submitted to the MLC concerning medical errors made in dental clinics in the Riyadh region of the KSA in order to identify the causes and outcomes of alleged dental malpractice. To the best of our knowledge, this study is one of the few research studies that examined dental malpractice across Saudi Arabia, especially in the Riyadh region. Understanding the causes and outcomes of dental malpractice litigation allows dentists and healthcare providers to gain insight into how to best care for their patients and to prevent such litigation. Furthermore, our findings can help officials decide on such issues and assist researchers in the management of dental facilities in finding new perspectives in scientific research. 


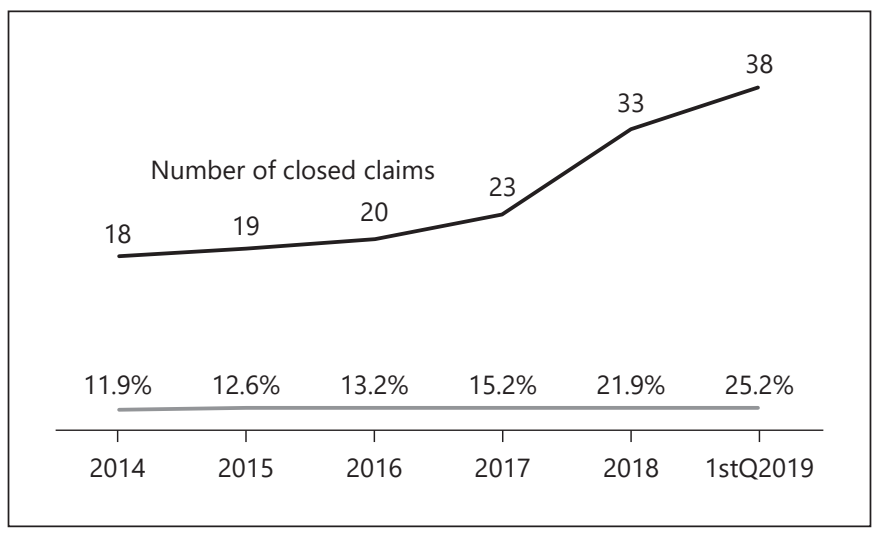

Fig. 1. Distribution of closed claims in terms of the ruling year.

\section{Materials and Methods}

This study is a retrospective review of the closed cases in dentistry as decided by the MLC, MOH in the Riyadh region of the KSA between January 1, 2014, and March 31, 2019. The data consist of recorded statements, experts' reviews, deposition summaries, and decision of committee report. Claims were reviewed in order to decide which cases will be included. The inclusion criteria were cases that had been adjudicated in the dentistry field during the period from January 1, 2014, to March 31, 2019, and for which the status is known to be closed. The exclusion criteria were as follows: duplicate claims, claims with inadequate documentation for review/lack of information, cases that were reopened, and cases that were not related to dentistry.

Data were developed and reviewed along with MLC team members. The data include information on the following: patient's demographics (gender and nationality), dentist's demographics (gender and nationality), year of litigation, defendant's qualification (intern, general dentist [GD], specialist, or consultant), dental specialty (oral surgery, dental implants, endodontics, periodontics, orthodontics, or prosthodontics), type of health sector where the medical service was provided $(\mathrm{MOH}$, private, other governmental entities), and the litigation's causes. The litigation causes were classified depending on the expert's opinion: misdiagnosis, failure to involve a specialist, treatment planning errors, failure to perform the procedure properly, poor documentation, lack of informed consent, or failure of disclosure. Meanwhile, the litigation outcomes were classified into 5 categories: a verdict in favor of the plaintiff, a verdict in favor of the defendant, settlement, withdrawn by the plaintiff, or the case being dismissed. The amount of compensation was recorded for both verdicts in favor of the plaintiff and settlement cases.

Data were coded and analyzed using descriptive analysis in the form of means and standard deviation, frequency, and percentages. This study analyzed all the data using the Statistical Package for Social Science version 23. Ethical approval for this research was obtained from the Research Committee at the General Department of Research and Studies in the MOH in Saudi Arabia (IRP No. 2019-0075M).
Table 1. Distribution of closed claims in terms of the facility type and dental specialty
Facility type

Ministry of Health

Private

Other government entities

Dental specialty

Prosthodontics

Endodontics

Orthodontics

Oral surgery

Dental implants

Periodontics
$N$

\section{$\%$}

\begin{tabular}{rr}
5 & 4 \\
144 & 95 \\
2 & 1 \\
53 & 35 \\
47 & 31 \\
24 & 16 \\
18 & 13 \\
8 & 5 \\
1 & 0.6 \\
\hline
\end{tabular}

\section{Results}

After the criteria were determined, the claims went through a review process aimed to screen the cases for inclusion in this study. All the closed claims in dentistry $(n=161)$ were taken from the MLC. After reviewing all the files, 151 cases were found to meet the criteria of this current study, whereas 10 cases were excluded because they were duplicated or lacking information.

As per our findings, there was an increase in the number of closed claims in dentistry, from 18 cases (11.9\%) in 2014 up to 38 cases $(25.17 \%$ ) in the first-quarter of 2019 , as shown in Figure 1. Table 1 shows the distribution of closed claims in terms of the facility type and dental specialty. It was also determined that 144 cases (95\%) of the complaints were against dentists working in the private sector. The dentistry specialties most involved in the complaints were prosthodontics (35\%) and endodontics (31\%).

Table 2 shows patient and dentist demographic characteristics. Approximately $52 \%$ of patients involved in the cases were female, while $48.3 \%$ were male. Most of them were Saudis $(88.7 \%)$, while only $11.3 \%$ were non-Saudis. Among the total number of dentists involved in the cases, 97 (61.8\%) were male, while $60(38.2 \%)$ were female. Most of the cases were filed against non-Saudis (94.3\%). The highest proportion of cases was against GDs (78.3\%), while $17.8 \%$ were against specialists.

The top common causes of litigation were as follows: failure to conduct the procedure properly $(31.5 \%)$, poor documentation (19.7\%), and lack of treatment plans (11.8\%). Figure 2 shows the full details on causes of litigation.

Table 3 shows the outcomes and compensations of dental malpractice litigation. Approximately, $54 \%$ of the 
Fig. 2. Causes of dental malpractice litiga-

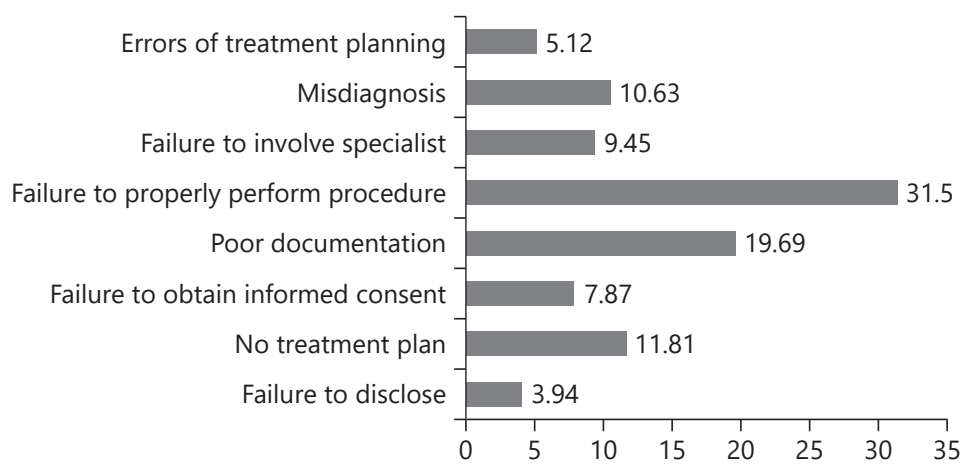
tion.

Table 2. Patient and dentist demographic characteristics

\begin{tabular}{lrr}
\hline & $N$ & $\%$ \\
\hline Patient characteristics & & \\
Gender & & \\
Male & 73 & 48.3 \\
Female & 78 & 51.7 \\
Nationality & & \\
$\quad$ Saudi & 134 & 88.7 \\
$\quad$ Non-Saudi & 17 & 11.3 \\
Dentist characteristics & & \\
Gender & 97 & \\
Male & 60 & 38.2 \\
Female & & \\
Nationality & 9 & 5.7 \\
$\quad$ Saudi & 148 & 94.3 \\
$\quad$ Non-Saudi & & \\
Qualification & 1 & 0.6 \\
Intern & 123 & 78.3 \\
$\quad$ General dentist & 28 & 17.8 \\
Specialist & 5 & 3.2 \\
$\quad$ Consultant & & \\
\end{tabular}

verdicts were in favor of the plaintiffs, $13 \%$ were passed in favor of the defendants, and $10 \%$ were dismissed. The average compensation in the settlement cases was 15,532 Saudi riyal (SR) (USD $1=3.75$ SR). On the other hand, the average compensation for the verdicts that were passed in favor of the plaintiff was 36,623 SR.

\section{Discussion/Conclusion}

Medical malpractice affects patient safety and increases healthcare cost. In this context, the increase in malpractice complaints in medical services could be attributed to ethical misconduct and technical negligence; un-
Table 3. Outcomes and compensations of dental malpractice litigation

\begin{tabular}{llc}
\hline Classification of outcomes & Cases, $n$ & \\
\hline Ruling in favor of defendant & 19 & 12.6 \\
Ruling in favor of plaintiff & 82 & 54.3 \\
Case dismissed & 15 & 9.9 \\
Settlement & 31 & 20.5 \\
Withdrawn by plaintiff & 4 & 2.6 \\
\hline Compensation amount & & \\
Compensation in settlement cases & Mean & $15,532.50 \mathrm{SR}$ \\
& Std. deviation & $11,738.10$ \\
& Median & $13,000 \mathrm{SR}$ \\
& Minimum & $800 \mathrm{SR}$ \\
& Maximum & $60,000 \mathrm{SR}$ \\
\hline Verdict in favor of plaintiff cases & Mean & $36,623.79 \mathrm{SR}$ \\
& Std. deviation & $42,777.94$ \\
& Median & $22,750 \mathrm{SR}$ \\
& Minimum & $300 \mathrm{SR}$ \\
& Maximum & $300,000 \mathrm{SR}$ \\
\hline
\end{tabular}

fortunately, dentists' failures in their duty can cause injuries, which might result from the improper use of dental equipment or incorrect dental instrument sterilization [17]. In the KSA, there has been a steady increase in the number of medical malpractice litigations and claims filed against healthcare providers and health practitioners; the published data show that the total number of medical malpractice claims referred to MLC increased from 2,778 to 4,732 during the period between 2014 and $2018[18,19]$. Previous studies have also indicated that this rising number of malpractice litigation cases can be attributed to the increasing number of healthcare practitioners and clinics, the growing number of the population having access to dental care services, and the popu- 
lation's awareness of their rights and in taking legal action [20].

Dentistry involves various specialties, including oral surgery, endodontics, periodontics, orthodontics, dental implants, and prosthodontics. In this study, prosthodontics was determined as the specialty most bombarded with complaints, which is consistent with the other studies' findings [20-22]. The high incidence of malpractice in prosthodontics is worthy of investigation due to the growing demand and aspirations of the new generations of prosthodontic patients [23]. In addition, each case contained one element or more of professional liability.

In this study, procedural error has been identified as the most frequent cause of litigation against dentists (31.5\%), as failure to perform a procedure properly can cause damage to patients. For instance, in endodontic clinics, the most frequently claimed treatment errors include the lack of a complete root canal(s) filling, the perforation of the tooth structure, sealing materials excessed the tooth apex, and breaking root canal treatment instruments inside the tooth [24]. This treatment error litigation cause is similar to finding of a previous study, which found that 87 cases out of 183 claims were due to procedural errors [25]. A popular explanation for the growing number of lawsuits in dentistry is the dentists' poor skills in performing their duty [26]. Furthermore, our findings have determined that some dentists poorly adhere to medical practice guidelines and conduct procedures that were beyond their competency.

On another note, documentation has been deemed essential in making the right decisions concerning professional conduct and assessing the claims properly. The dentist performing a procedure is usually required to provide all relevant case-related documents, such as the patient's file and X-rays before, during, and after treatment [24]. In this study, poor documentation was the second most common cause of litigation. This is in line with what has been found in a previous study that identified that most of the cases had poor or no documentation at all [27]. This result indicates the importance of documenting medical intervention steps by keeping a proper dental record.

There are 5 ethical principles in dentistry practice, which are as follows: no harm, respect, trust, beneficence, and equity [28]. Effective patient-dentist relationships are required for a successful treatment plan. The dentist determines the specific needs and the treatment method, and a successful treatment plan includes a short-, medium-, and long-term view, dealing with patients as individuals, not just treating them as a problem that needs to be fixed, which requires appropriate knowledge, communication skills, common sense, and clinical skills [29]. The results showed that approximately $12 \%$ of litigation cases were due to lacking treatment plan, while about $5 \%$ were due to errors in the treatment plans. A proper treatment plan is used as a practice management tool to make dentists, patients, and other staff aware of the performed procedures, the treatment sequences, and the service fees to be charged [29]. Any errors, or working without a proper treatment plan, can lead to undesirable treatment outcomes.

The wrong diagnoses can cause permanent or temporary damage to the patient. As per our findings, misdiagnosis accounted for $10.63 \%$ of the total claims. Similarly, in 2009 , a study that analyzed dental malpractice claims in Tehran found that $11.5 \%$ of allegations in the total number of claims were related to diagnosis errors [22]. Miscommunication, poor patient management, and lacking knowledge and skills are considered contributing factors to misdiagnosis [30]. The possible risk factors in dentistry can be controlled by providing high-quality dental care and maintaining a strong relationship between the treatment quality and the success outcomes [31].

When a case is beyond the scope of the dentist's experience, GDs must refer the case to a specialist, and the referral should be documented in the patient's file. This study observed that about $79 \%$ of defendants were GDs who were only supposed to carry out basic procedures, but provided advanced services such as prosthodontics or endodontics, which should only be performed by specialists. These advanced services by GDs are considered a violation of Article 9 of the Law of Practicing Healthcare Professions of Saudi Arabia [11]. Findings from a previous research conducted in Brazil and Iran have also found that the majority of dental malpractice claims were against GDs $[26,32]$.

One of the major medical ethical challenges facing healthcare practitioners in the KSA is informed consent, which might be due to language barriers or miscommunication [33]. There is debate around the degree of detail to be disclosed on obtaining informed consent forms from patients and the disclosure method to be adopted. Patients often do not read consent forms, and, even when they do, the forms' readability is poor, and the content is often misunderstood. Even if the consent forms' readability and the informers' efficiency (dentists in this case) are maintained, clinicians must try to decide if patients really understand all the data given to them [34]. This current study found that failure to obtain informed consent accounted for approximately $8 \%$ of the malpractice cases. 
Findings from a previous research have also found that the lack of informed consent was a common reason for oral maxillofacial malpractice [25]. Obtaining informed consent has become a critical standard for maintaining patients' legal rights and directing professional ethical practice. Informed consent can be used for legal, ethical, or administrative purposes, and physicians can record the details of these interactions to have evidence of their actions in legal terms [35].

Ethically, healthcare professionals have an obligation to disclose harmful errors or treatment complications. Error disclosure can improve both patient safety and care quality, but the dilemma lies on how to disclose the error or harmful event [36]. A previous study into professional dental staff's attitudes regarding medical error disclosure showed that the majority of participants believe that dental errors must be disclosed and that health workers in the public sector are more likely to disclose their medical errors than those working in the private sector [37].

In relation to the claims' outcomes, in $54.3 \%$ of the cases, the verdict was passed in favor of the patients, finding the dental practitioner guilty. This high rate is in line with other studies in which the dentists were found guilty in $74 \%$ of the studied claims [21]. In the Saudi system, civil liability is the main route for filing a lawsuit in private disputes, and the compensation amount in Saudi law is based on Islamic Shariah. The MLC determines the compensation amount in malpractice cases [3]. The results also showed that the average payout amount in settlement cases was 15,532 SR and 36,623 SR in case of verdicts in favor of the plaintiff. This is much lower compared to that in the USA where the average payout amount was about USD 785,000 in settlement cases, with the payout where the verdict favored the plaintiff ranging from USD 13,750 to $15,000,000$ [25].

This research has highlighted that the most common malpractice lawsuit filed against dentists is due to poor outcomes. The results indicate that failure to conduct a procedure properly is the most common issue leading to litigation, and more than half of these cases have found dentists guilty, so the right to carry out dental procedures should be clarified and defined by the official dental committee for both sectors based on the rank and subspecialty of the dentist involved (GDs, specialists, and consultants). A checklist of the minimum requirements for dental records should be kept inside the patients' files to ensure the dentists' compliance with proper records before, during, and after the procedures. In addition, the Saudi Commission for Health Specialties should add a section related to the Law of Practicing Healthcare Pro- fessionals of Saudi Arabia in the Saudi Dental Licensure Examination. Finally, further research is warranted to identify the types of procedural errors leading to dental malpractice and their associated factors.

\section{Acknowledgment}

The authors acknowledge and thank Dr. Ali Alromikan, Orthodontics Consultant and Member of General Secretariat of the Medico-Legal Committee at the Ministry of Health, and Mr. Khaled Alzhrani, General Director of Archives and Records Center at the Ministry of Health, for their support.

\section{Statement of Ethics}

The research study was approved by the Central Institutional Review Board at the General Department of Research and Studies in the Ministry of Health in Saudi Arabia (IRP No. 2019-0075M). Informed consent is not required for this type of study.

\section{Conflict of Interest Statement}

The authors have no conflicts of interest to declare.

\section{Funding Sources}

The authors received no specific funding for this work.

\section{Author Contributions}

A.S.A. conceived the idea, designed the study, and analyzed and interpreted the data under supervision from M.A.A. and M.K.A. at King Abdulaziz University as part of A.S.A.'s master research project. A.S.A. drafted the first draft of the manuscript. M.A.A. and M.K.A. reviewed and suggested the structure of the manuscript. All authors contributed to revisions of the manuscript and approved the final version of the manuscript prior to its submission. A.S.A. is the overall guarantor for this work.

References

1 WHO. Global action on patient safety. The Seventy-second World Health Assembly; https: //apps.who.int/gb/ebwha/pdf_files/ WHA72/A72_R6-en.pdf.

2 Oglesby AM. Analysis of emergency medicine incidents and completed closed claims/[Theses] by Anne Marie Oglesby. University College Dublin (UCD); 2009.

3 Alkhenizan AH, Shafiq MR. The process of litigation for medical errors in Saudi Arabia and the United Kingdom. Saudi Med J. 2018; 39(11):1075. 
4 Blau I, Levin L. Medical malpractice: an introduction for the dental practitioner. Quintessence Int. 2017;48(10):835.

5 Stevenson A. Oxford dictionary of English. New York, NY: Oxford University Press; 2010.

6 Hurwitz B. Clinical guidelines and the law: negligence, discretion, and judgement. CRC Press; 2018.

7 Reamer FG. Risk management in social work: preventing professional malpractice, liability, and disciplinary action. Columbia University Press; 2014.

8 Moffett P, Moore G. The standard of care: legal history and definitions: the bad and good news. West J Emerg Med. 2011;12(1):109.

9 Bryden D, Storey I. Duty of care and medical negligence. Cont Educ Anaesth Crit Care Pain. 2011;11(4):124-7.

10 Todd NV. Causes and outcomes of cauda equina syndrome in medico-legal practice: a single neurosurgical experience of 40 consecutive cases. Br J Neurosurg. 2011;25(4):503-8.

$11 \mathrm{MOH}$. Ministry of health: law of practicing Healthcare Profession. 2020 [cited 2020 Jul 10]. Available from: https://www.moh.gov. sa/en/Ministry/Rules/Pages/default.aspx.

12 Al-Saeed AH. Medical liability litigation in Saudi Arabia. Saudi J Anaesth. 2010;4(3):122.

13 Ghaffar UB, Ahmed SM, Faraz A. A review of the frequency of medical error in Saudi Arabia: an emerging concern. J Evid Based Med Healthcare. 2015;2(52):8692-5.

14 AlJarallah JS, AlRowaiss N. The pattern of medical errors and litigation against doctors in Saudi Arabia. J Family Community Med. 2013;20(2):98.

15 AlDakhil LO. Obstetric and gynecologic malpractice claims in Saudi Arabia: incidence and cause. J Forensic Leg Med. 2016;40:8-11.

16 Perea-Pérez B, Labajo-González E, SantiagoSáez A, Albarrán-Juan E, Villa-Vigil A. Analysis of 415 adverse events in dental practice in Spain from 2000 to 2010. Med Oral Patol Oral Cir Bucal. 2014;19(5):e500
17 Di Lorenzo P, Paternoster M, Nugnes M, Pantaleo G, Graziano V, Niola M. Professional dental and oral surgery liability in Italy: a comparative analysis of the insurance products offered to health workers. Open Med. 2016;11(1):256-63

$18 \mathrm{MOH}$. Ministry of Health: Statistical Yearbook; 2014 [cited 2020 Oct 15]. Available from: https://www.moh.gov.sa/en/Ministry/ Statistics/book/Documents/Statistical-Bookfor-the-Year-1435.pdf.

$19 \mathrm{MOH}$. Ministry of Health: Statistical Yearbook; 2018 [cited 2020 Oct 15]. Available from: https://www.moh.gov.sa/en/Ministry/ Statistics/book/Documents/book-Statistics. pdf.

20 Zanin AA, Herrera LM, Melani RFH. Civil liability: characterization of the demand for lawsuits against dentists. Braz Oral Res. 2016; $30(1)$.

21 Manca R, Bruti V, Napoletano S, Marinelli E. A 15 years survey for dental malpractice claims in Rome, Italy. J Forensic Leg Med. 2018;58:74-7.

22 Kiani M, Sheikhazadi A. A five-year survey for dental malpractice claims in Tehran, Iran. J Forensic Leg Med. 2009;16(2):76-82.

23 Nassani MZ. Aspects of malpractice in prosthodontics. J Prosthodont. 2017;26(8): 672-81.

24 Pinchi V, Pradella F, Gasparetto L, Norelli G-A. Trends in endodontic claims in Italy. Int Dent J. 2013;63(1):43-8.

25 He P, Mah-Ginn K, Karhade DS, Donoff B, Adeeb N, Gupta R, et al. How often do oral maxillofacial surgeons lose malpractice cases and why? J Oral Maxillofac Surg. 2019;77(12): 2422-30.

26 Rovida TAS, de Dias IA, Garbin CAS, Garbin AJI, Rovida T, Dias I, et al. Evaluation of injury cases for dental intervention described in legal dentistry reports. Int J Odontostomat. 2015;9(3):533-9.
27 Pinchi V, Varvara G, Pradella F, Focardi M, Donati MD, Norelli G. Analysis of professional malpractice claims in implant dentistry in Italy from insurance company technical reports, 2006 to 2010. Int J Oral Maxillofac Implants. 2014;29(5):1177.

28 Bhadauria US, Sandesh N, Mishra P, Godha S. Medico-legal aspect of dental practice. Clujul Med. 2018;91(3):255.

29 Newsome P, Smales R, Yip K. Oral diagnosis and treatment planning: part 1. Introduction. Br Dent J. 2012;213(1):15-9.

30 Nikdel C, Nikdel K, Ibarra-Noriega A, Kalenderian E, Walji MF. Clinical dental faculty members' perceptions of diagnostic errors and how to avoid them. J Dent Educ. 2018; 82(4):340-8.

31 Jadhav A, Kumar S, Acharya S, Bhalinge P, Ganta S. Patient safety practices in dentistry: a review. Int J Sci Study. 2016;3(10):163-5.

32 Hashemipour MA, Pour FM, Lotfi S, Nassab AHG, Rahro M, Dadgar MM. Evaluation of dental malpractice cases in Kerman province (2000-2011). J Forensic Leg Med. 2013;20(7): 933-8.

33 Alkabba AF, Hussein GM, Albar AA, Bahnassy AA, Qadi M. The major medical ethical challenges facing the public and healthcare providers in Saudi Arabia. J Family Community Med. 2012;19(1):1.

34 Reid KI. Informed consent in dentistry. J Law Med Ethics. 2017;45(1):77-94.

35 Hall DE, Prochazka AV, Fink AS. Informed consent for clinical treatment. CMAJ. 2012, 184(5):533-40.

36 Barach P, Cantor M. Adverse event disclosure: benefits and drawbacks for patients and clinicians. Informed Consent and Clinician Accountability; 2007. p. 76.

37 Al-Nomay NS, Ashi A, Al-Hargan A, Alshalhoub A, Masuadi E. Attitudes of dental professional staff and auxiliaries in Riyadh, Saudi Arabia, toward disclosure of medical errors. Saudi Dent J. 2017;29(2):59-65 